\title{
COMMENTARY
}

\section{A strategy for obesity control: repetition is the key}

\author{
Yusuke Ohya \\ Hypertension Research (2011) 34, 548; doi:10.1038/hr.2011.20; published online 10 March 2011
}

$\mathrm{T}$ he prevalence of obesity is increasing in Japan and in many other countries; it presents a major public health issue because obesity is related to a variety of metabolic and cardiovascular diseases. Obesity is a fataccumulating condition caused by an imbalance between energetic intake and output, as well as ineffective energy usage. ${ }^{1}$ Thus, the strategy for controlling obesity is theoretically simple-that is, eat less and exercise more. However, this healthy lifestyle approach is often unsuccessful in controlling obesity. The development of an effective and simple program for the prevention of obesity and metabolic syndrome is emerging. ${ }^{2}$ There have been only a limited number of anti-obesity programs that have been validated by randomized and controlled studies. ${ }^{3,4}$ Because socio-cultural backgrounds differ among areas and countries, a casespecific strategy for promoting healthy lifestyles might provide improved results. ${ }^{1}$ The study by Munakata et al. ${ }^{5}$ in this issue uses a randomized trial and clearly demonstrates that, in comparison with single counseling, repeated counseling provides improved health effects for Japanese workers. Interestingly, the effects observed in this study were most evident in waist circumference and fasting blood sugar levels, but were not related to blood pressure. This result suggests that the repeated-counseling strategy in this study for controlling obesity might have some limitations for preventing hypertension. Furthermore, because obese study subjects frequently re-gain weight, the long-term effects of this strategy should be clarified in future studies. ${ }^{6}$
1 Sharma AM, Padwal R. Obesity is a sign-over-eating is a symptom: an aetiological framework for the assessment and management of obesity. Obes Rev 2010; 11: 362-370.

2 Dagogo-Jack S, Egbuonu N, Edeoga C. Principles and practice of nonpharmacological interventions to reduce cardiometabolic risk. Med Princ Pract 2010; 19: 167-175.

3 Brown T, Avenell A, Edmunds LD, Moore H, Whittaker V, Avery L, Summerbell C. Systematic review of long-term lifestyle interventions to prevent weight gain and morbidity in adults. Obes Rev 2009; 10: 627-638.

4 Maruyama C, Kimura M, Okumura H, Hayashi K, Arao T. Effect of a worksite-based intervention program on metabolic parameters in middle-aged male white-collar workers: a randomized controlled trial. Prev Med 2010; 51: 11-17. 5 Munakata M, Honma H, Akasi M, Araki T, Kawamura T, Kubota M, Yokokawa T, Numata Y, Toyonaga T, on behalf of the J-STOP-MetS Study Group. Repeated counselling improves the antidiabetic effects of limited individualized lifestyle guidance in metabolic syndrome: J-STOP-METS final results. Hypertens Res 2011; 34: 612-616.

6 Sarwer DB, von Sydow Green A, Vetter ML, Wadden TA. Behavior therapy for obesity: where are we now? Curr Opin Endocrinol Diabetes Obes 2009; 16: 347-352. 